\title{
Implementasi E-learning Ujian Online Dalam Menghadapi Ujian Nasional Berbasis Komputer Pada SMAN 5 Dumai
}

\author{
Teuku Radillah ${ }^{1}$, Hayatullah Khumaini ${ }^{2}$, Amat Sofiyan ${ }^{3}$ \\ Program Studi Teknik Informatika, Sekolah Tinggi Manajemen Informatika dan \\ Komputer (STMIK) Dumai \\ Jl. Utama Karya Bukit Batrem II \\ Email: t.radillah@gmail.com
}

\begin{abstract}
ABSTRAK
SMA Negeri 5 Dumai merupakan sekolah menengah negeri atas yang terletak di jalan M.Yusuf Kecamatan Medang kampai. Posisi sekolah tersebut termasuk salah satu sekolah yang jauh dari jangkauan Kota Dumai, sehingga untuk akses internet sebagai media pembelajaran secara online sangatlah minim didaerah ini. Untuk proses Ujian Nasional Berbasis Komputer (UNBK) SMAN 5 Negeri Dumai mengandalkan tower dengan jaringan internet yang telah disubsidi dari dinaspendidikan kota Dumai. Minimnya fasilitas internet untuk belajar mencari referensi secara online dan latar belakang siswa yang kurang mampu menyebabkan siswa dilingkungan SMAN 5 Dumai kurang memahami dalam pengoperasian dan penggunaan komputer sebagai media pembelajaran, sementara proses UNBK dilakukan secara online dan saat ini hampir semua sekolah yang mengikuti UNBK termasuk SMAN 5 Dumai tidak memiliki aplikasi UNBK yang bersifat lokal yang dapat digunakan siswa sebagai media training atau pelatihan. Kesenjangan antara kemampuan terhadap pengetahuan penggunaan komputer dengan kompetensi ujian yang dilakukan secara komputer membuat angka kegagalan dalam menghadapi UNBK tersebut sangat tinggi. Untuk meningkatkan kualitas siswa dalam menghadapi UNBK tersebut diperlukan suatu aplikasi e-learning ujiann online yang memuat mteri pembelajaran sebagai training atau pelatihan pembekalan kemampuan siswa sebelum menghadapi UNBK tersebut. Aplikasi E-learning ujian online tersebut dapat dijalankan secara intranet maupun secara online dengan memanfaatkan internet disekolah, dan dengan adanya Aplikasi E-learning ujian online ini menjadi solusi dalam meminimalisir angka kegagalan siswa dalam menghadapi UNBK khususnya pada SMAN 5 Dumai.
\end{abstract}

Kata kunci: SMAN 5 Dumai, UNBK, E-learning, Training, Online

\section{ABSTRACT}

SMA Negeri 5 Dumai is a state high school located on Jalan M.Yusuf, in Medang Kampai Subdistrict. The position of the school is one of the schools that is far from the reach of Dumai City, so that to access the internet as a medium of online learning is very minimal in this area. For the Computer-Based National Examination (UNBK)

UNITEX Vol 11 No.2 Juli - Desember 2018 | p-ISSN 2089-3957 | e-ISSN 2580-2585 
process of State Senior High School 5 Dumai relies on a tower with an internet network that has been subsidized from the education office of the city of Dumai. The lack of internet facilities to learn to look for references online and the background of students who are less able to cause students in SMAN 5 Dumai to lack understanding in the operation and use of computers as learning media, while the UNBK process is done online and currently almost all schools that participate in UNBK include SMAN 5 Dumai does not have a local UNBK application that can be used by students as a medium of training or training. The gap between the ability to know how to use computers and the competence of tests conducted on a computer makes the number of failures in dealing with UNBK very high. To improve the quality of students in dealing with UNBK, an online e-learning application is needed that contains learning material as training or training in students' ability before facing the UNBK. The online exam E-learning application can be run intranet or online by utilizing the internet at school, and with the E-learning Application this online exam is a solution in minimizing the number of student failures in dealing with UNBK, especially in SMAN 5 Dumai.

Keywords: SMAN 5 Dumai, UNBK, E-learning, Training, Online

\section{Pendahuluan}

SMA Negeri 5 Dumai merupakan sekolah menengah negeri atas yang terletak di jalan M.Yusuf Kecamatan Medang kampai. Posisi sekolah tersebut termasuk salah satu sekolah yang jauh dari jangkauan Kota Dumai, sehingga untuk akses internet sebagai media pembelajaran secara online sangatlah minim didaerah ini. Untuk proses Ujian Nasional Berbasis Komputer (UNBK) SMAN 5 Negeri Dumai mengandalkan tower dengan jaringan internet yang telah disubsidi dari dinas pendidikan kota Dumai. Minimnya fasilitas internet untuk belajar mencari refrensi secara online dan latar belakang siswa yang kurang mampu menyebabkan siswa dilingkungan SMAN 5 Dumai kurang memahami dalam pengoperasian dan penggunaan komputer sebagai media pembelajaran, sementara proses UNBK dilakukan secara online dan saat ini hampir semua sekolah yang mengikuti UNBK termasuk SMAN 5 Dumai tidak memiliki aplikasi UNBK yang bersifat lokal yang dapat digunakan siswa sebagai media training atau pelatihan.

Kesenjangan antara kemampuan terhadap pengetahuan penggunaan komputer dengan kompetensi ujian yang dilakukan secara komputer membuat angka kegagalan dalam menghadapi UNBK tersebut sangat tinggi. Untuk meningkatkan kualitas siswa dalam menghadapi UNBK tersebut diperlukan suatu aplikasi e-learning ujiann online yang memuat mteri pembelajaran sebagai training atau pelatihan pembekalan kemampuan siswa sebelum menghadapi UNBK tersebut. Aplikasi E-learning ujian online tersebut dapat dijalankan secara intranet

UNITEX Vol 11 No.2 Juli - Desember 2018 | p-ISSN 2089-3957 | e-ISSN 2580-2585 
maupun secara online dengan memanfaatkan internet disekolah, dan dengan adanya Aplikasi E-learning ujian online ini menjadi solusi dalam meminimalisir angka kegagalan siswa dalam menghadapi UNBK khususnya pada SMAN 5 Dumai. Berdasarkan identifikasi masalah diatas, maka dapat dirumuskan permasalahan pada penelitian ini yaitu bagaimana membuat sistem pembelajaran ujian online (elearning) dalam menghadapi ujian nasional berbasis komputer (UNBK) untuk meminimalisir angka kegagalan sisa pada SMAN 5 Dumai.

Adapun tujuan penelitian secara global yang dilakukan adalah memberikan pemahaman serta meningkatkan pengetahuan kepada mahasiswa tentang penggunaan sistem ujian online berbasis komputerisasi dan memberikan pelatihan kepada siswa untuk dapat beradaptasi dalam menghadapi UNBK, sehingga dapat meningkatkan kualitas siswa dalam pencapaian pembelajaran.

\section{Metode Penelitian}

\section{Implementasi Metode Penelitian}

Metodologi untuk Pengembangan Sistem merupakan proses standar yang digunakan team pengembang untuk menghubungkan semua langkah yang diperlukan untuk menganalisa, merancang, mengimplementasi, dan memelihara SI. Adapun metodologi yang sampai saat ini masih sesuai untuk menjadi pedoman dalam pengembangan sistem adalah SDLC. System Development Life Cycle (SDLC) adalah metodologi yang digunakan untuk mengembangkan, memelihara, dan/atau mengganti SI. Gambar 1 menggambarkan bagan dari SDLC yang umum dimana terdiri atas 7 phase, berikut adalah bagan dari sehingga SDLC juga sering disebut metodologi 'Waterfall' karena lebih menyerupai air terjun.

UNITEX Vol 11 No.2 Juli - Desember 2018 | p-ISSN 2089-3957 | e-ISSN 2580-2585 


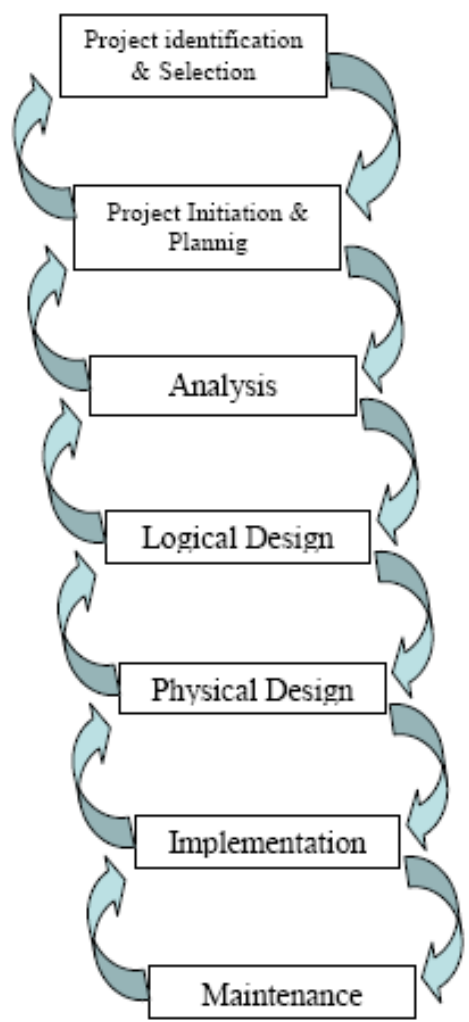

Gambar 1. SDLC dengan ke-7 phasenya

\section{Output atau produk yang dihasilkan ditiap phase SDLC}

\section{a. Project Identification \& Selection, menghasilkan}

Yang berhubungan dengan aktifitas perencanaan Sistem, yaitu menentukan prioritas sistem dan proyek, arsitektur dari data, hardware, dan manajemen dari system informasi. Pada fase ini akan dilakukan identifikasi soal-soal yang akan dijadilan latihan menghadapi UNBK di SMAN 5 Dumai.

\section{b. Project Initiation \& Planning, menghasilkan:}

Langkah terperinci atau rencana kerja untuk proyek, spesifikasi dari ruang lingkup sistem dan syarat/bentuk sistem (high-level), tugas untuk anggota team dan sumber daya lainnya, sistem perundangan /pertimbangan sistem yang akan dibangun.

c. Analysis, menghasilkan:

Penjabaran mengenai sistem yang ada termasuk masalah atau peluang yang ada yang direkomendasi untuk di perbaiki/ diatasi, ditingkatkan, atau mengganti sistem yang ada, uraian mengenai sistem pilihan dan sistem perundangan /pertimbangan untuk sistem yang terpilih, Mulai dari

UNITEX Vol 11 No.2 Juli - Desember 2018 | p-ISSN 2089-3957 | e-ISSN 2580-2585 
menentukan lokasi shelter secara manual, kemudian kesulitan yang ditemui waktu pencarian shelter tersebut dan menemukan berbagai solusi untuk mengatasi berbagai hambatan yang ditemukan.

d. Logical Design, menghasilkan:

Berhubungan dengan fungsi-fungsi, spesifikasi terperinci dari semua elemen sistem (data, proses, input, output) Pada fase ini mulai melakukan desain data-data apa saja yang dibutuhkan untuk mencari data soal ujian sesuai dengan jadwal dan mata pelajaran yang dipilih, proses yang dibutuhkan input dan output yang diharapakan berupa hasil perhitungan index kelulusan siswa dalam mengerjakan soal ujian e-learning berbasis online.

\section{e. Physical Design, menghasilkan:}

Lebih bersifat teknis, spesifikasi terperinci dari semua elemen sistem (program, file-file, jaringan, sistem software, dll), rencana untuk teknologi baru. Disini Sistem sudah dibuatkan berbasis online sehingga bisa diakses dimanapun dengan adanya jangkauan jaringan internet.

f. Implementation, menghasilkan:

Code/listing program, dokumentasi, prosedur pelatihan, dan support /dukungan yang dapat diberikan.

g. Maintenance, menghasilkan:

Software versi terbaru atau dengan pembaruan untuk dokumentasi, pelatihan, support/dukungan.

\section{Hasil dan Pembahasan}

\section{Analisa Proses}

Untuk merancang suatu aplikasi ujian nasional berbasis komputer secara online dibutuhkan proses sistem keamanan login yang terenkripsi sampai alur penginputan data soal yang akan dijawab akan dianalisa untuk menentukan pengelompokan jawaban yang benar sehingga menghasilkan suatu laporan yang disajikan dalam bentuk table-tabel yang berelasi pada setiap mata pelajaran.

\section{Gambaran Proses Pengerjaan Soal UNBK}

Untuk login pada aplikasi, admin terlebih dahulu menginput data siswa dan data soal. Selanjutnya siswa melakukan login berdasarkan nis (no induk siswa) masing-masing dan sistem akan otomatis menampilkan pilihan soal soal 
berdasarkan jurusan siswa, berikut gambaran proses pengerjaan soal soal UNBK dapat dilihat pada Gambar 2.

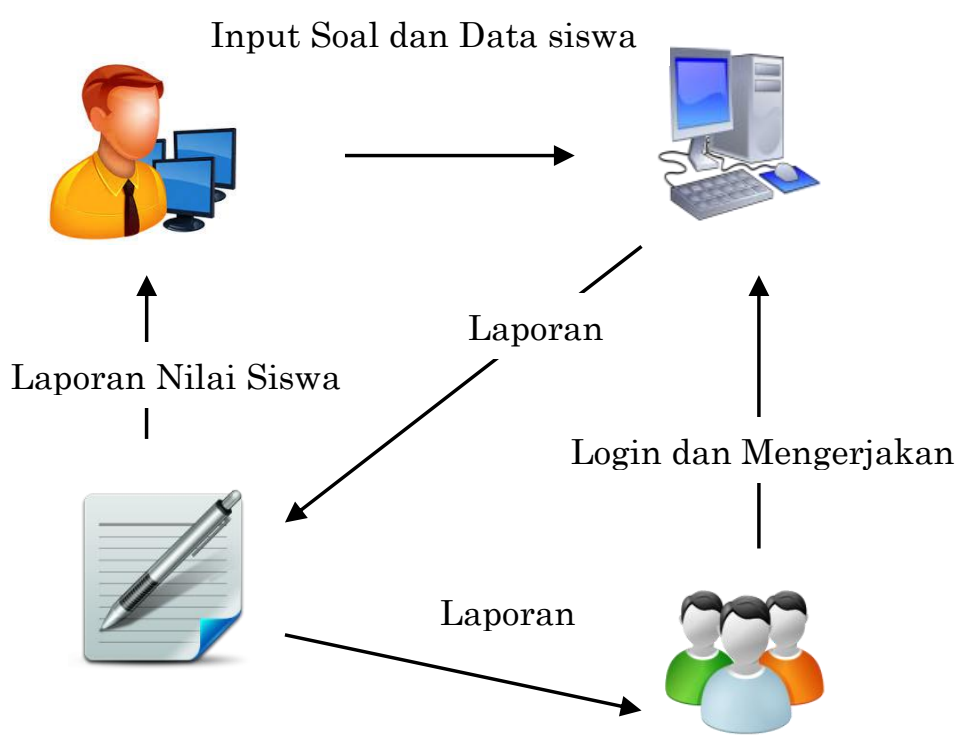

Gambar 2. Proses pengerjaan soal UNBK

\section{Hasil Implementasi}

Implementasi merupakan proses kelanjutan dari kegiatan perancangan sistem dan merupakan usaha untuk mewujudkan system yang dirancang. Langkah -langkah dari proses implementasi adalah urutan dari kegiatan awal sampai kegiatan akhir yang dilakukan dalam mewujudkan sistem yang dirancang. Untuk mewujudkan sistem tersebut dibutuhkan dukungan komponen-komponen dalam implementasi terhadap system yang digunakan, seperti kebutuhan komponen hardware dan software. Adapun hasil implementasi aplikasi UNBK pada SMA N 5 Dumai sebagai berikut:

1. Untuk login dari aplikasi user harus login dengan menginput user dan password dengan benar, setelah user dan password benar, selanjutnya klik tombol login dan aplikasi otomatis masuk kedalam menu utama.

UNITEX Vol 11 No.2 Juli - Desember 2018 | p-ISSN 2089-3957 | e-ISSN 2580-2585 


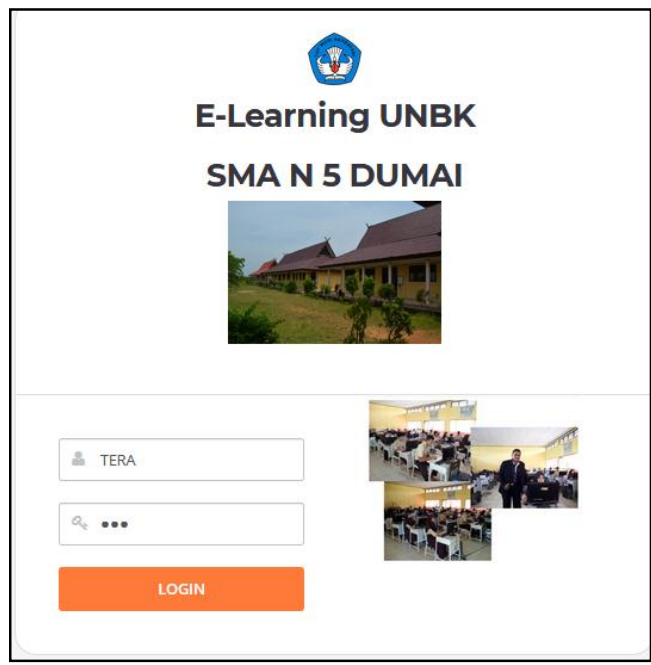

Gambar 3. Login aplikasi

2. Selanjutnya Admin menginput data siswa

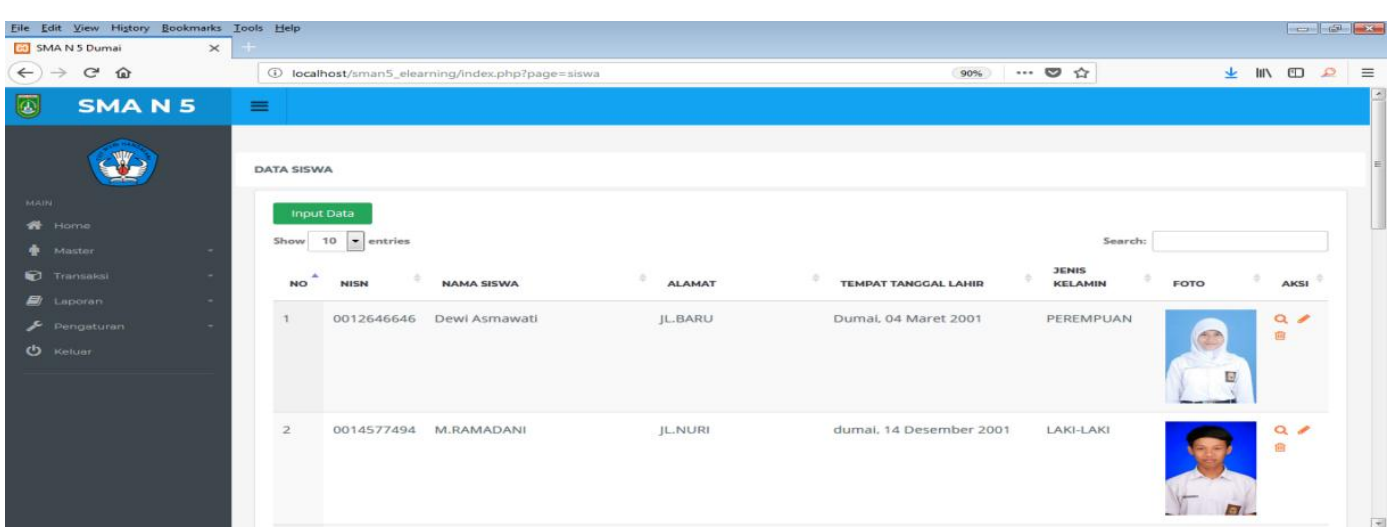

Gambar 4. Data siswa

UNITEX Vol 11 No.2 Juli - Desember 2018 | p-ISSN 2089-3957 | e-ISSN 2580-2585 
3. Siswa Jurusan IPA memilih soal e-learning UNBK

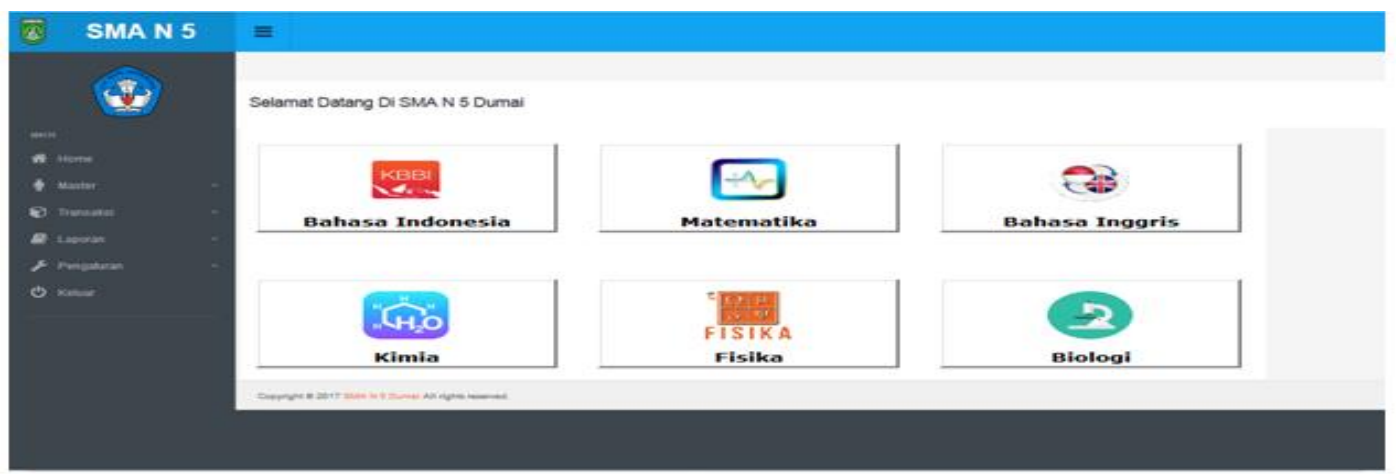

Gambar 5. Menu pilihan soal IPA

4. Soal e-learning UNBK Matematika

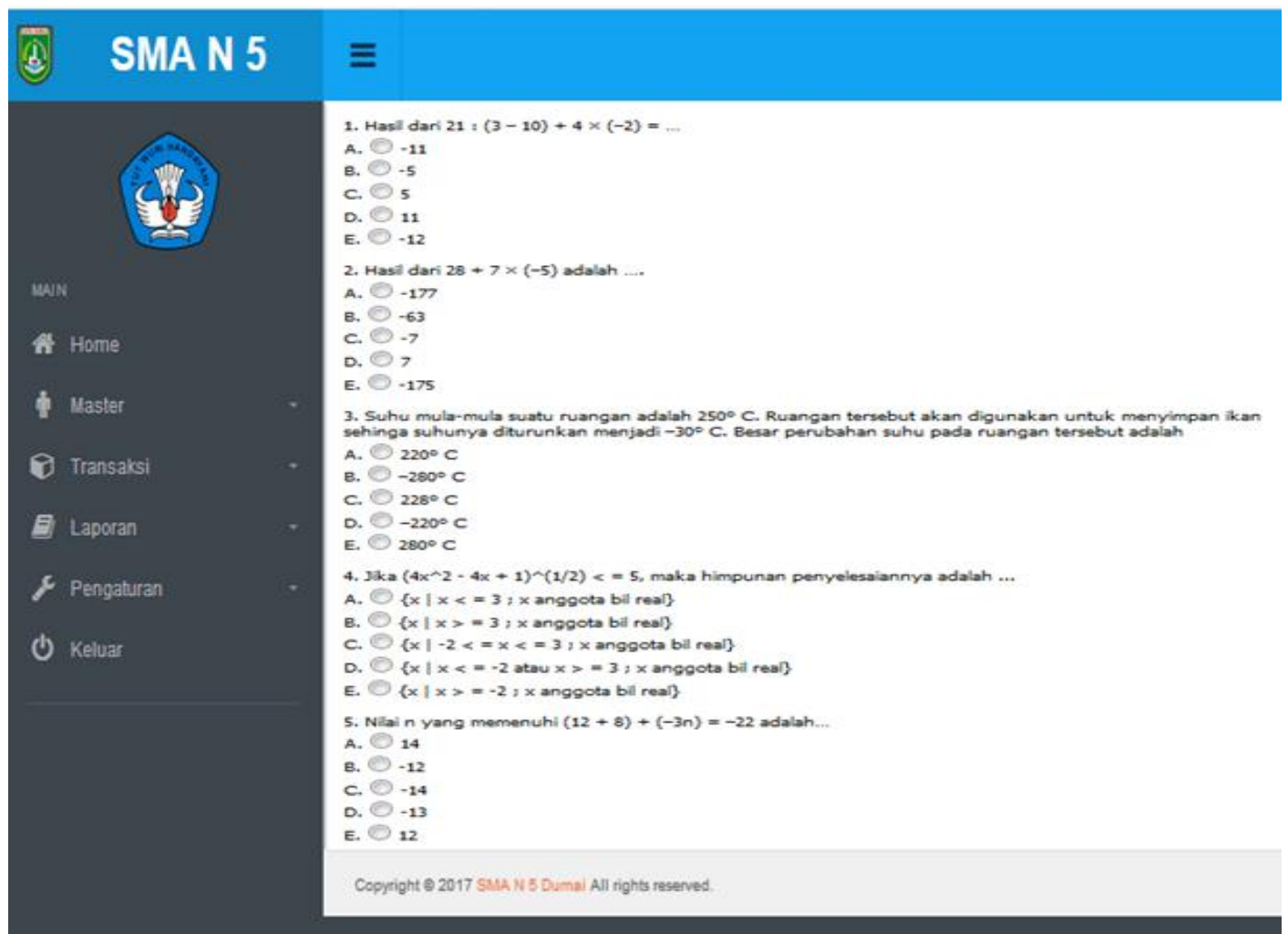

Gambar 6. Soal UNBK matematika

UNITEX Vol 11 No.2 Juli - Desember 2018 | p-ISSN 2089-3957 | e-ISSN 2580-2585 
5. Siswa Jurusan IPS memilih soal e-learning UNBK

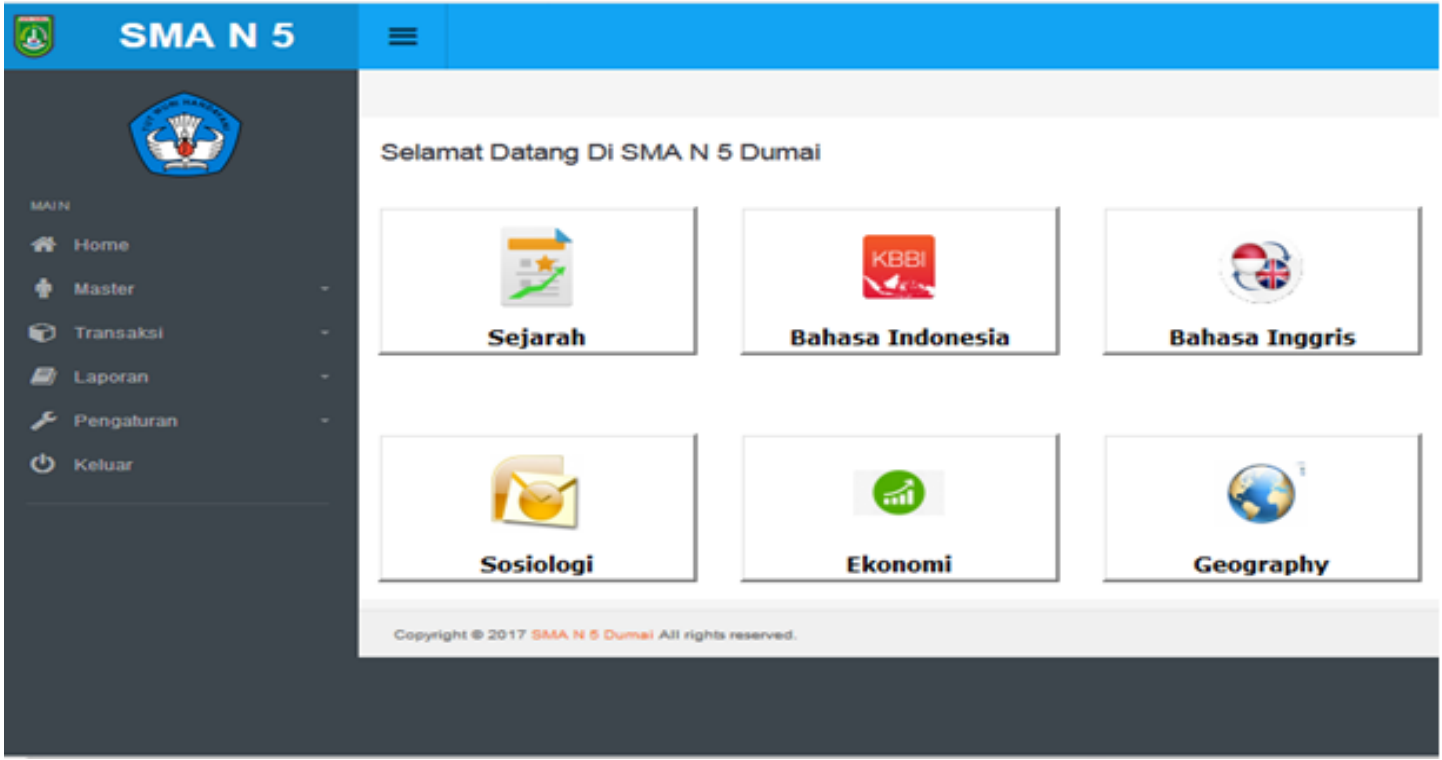

Gambar 7. Menu pilihan soal IPS

UNITEX Vol 11 No.2 Juli - Desember 2018 | p-ISSN 2089-3957 | e-ISSN 2580-2585 
6. Soal e-learning UNBK Geography

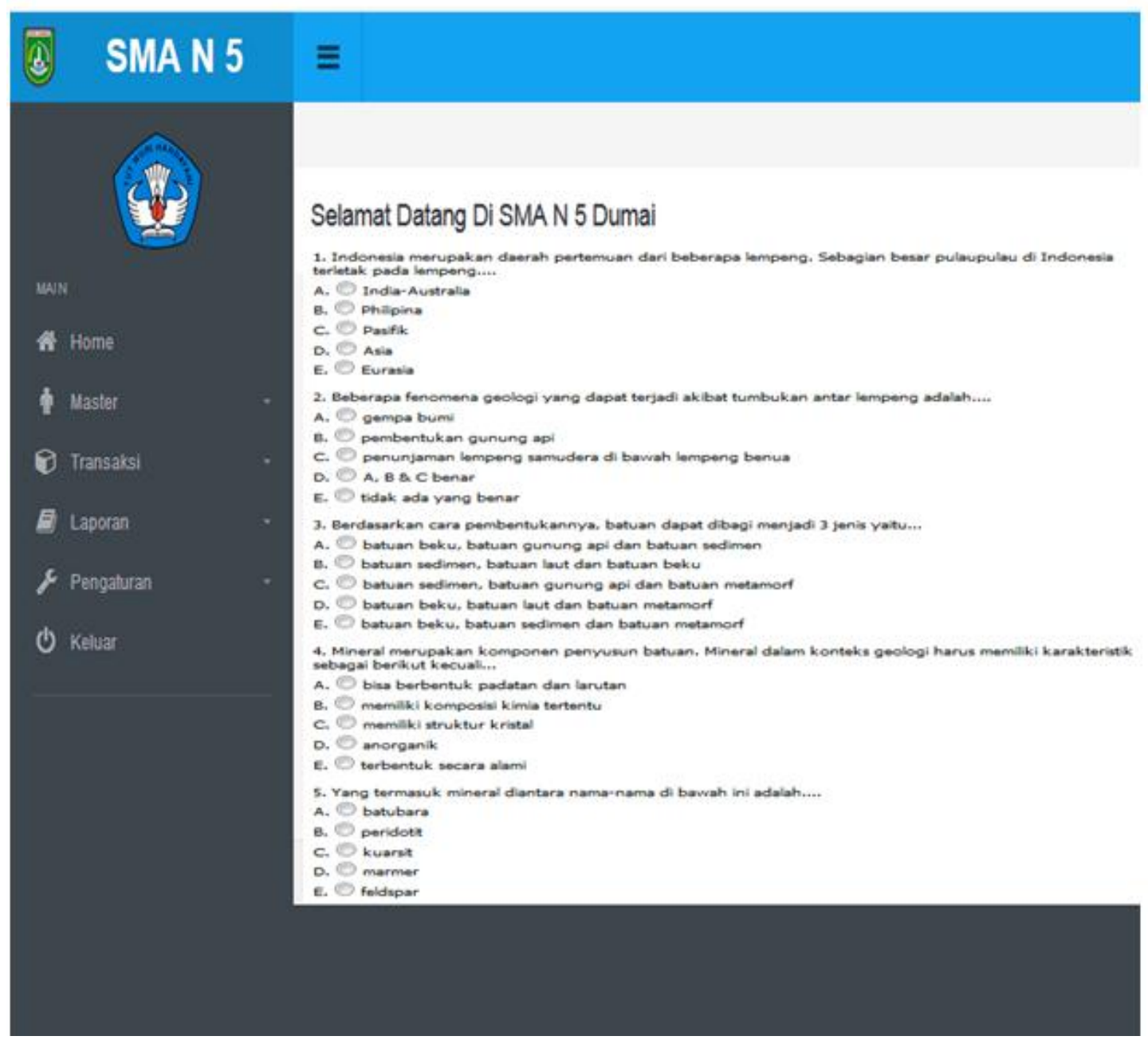

Gambar 8. Soal UNBK geography

\section{Simpulan}

Dari uraian tersebut yang telah dibahas sebelumnya dapat ditarik kesimpulan sebagai berikut :

1. Berdasarkan penerapan uji coba yang dilakukan memberikan kemajuan signifikan pada setiap siswa dalam pengoperasian komputer dan terbiasa menjawab soal ujian secara komputerisasi.

UNITEX Vol 11 No.2 Juli - Desember 2018 | p-ISSN 2089-3957 | e-ISSN 2580-2585 
2. Soal ujian dapat diakses oleh siswa setiap jurusan dengan tampilan menu pilihan soal permata pelajaran yang mudah digunakan.

3. Setiap siswa dapat melakukan evaluasi kemampuan diri masing-masing dengan melihat hasil ujian yang telah dilakukan.

\section{Daftar Pustaka}

Al-Fatta, Hanif, (2008), "Analisa \& Perancangan Sistem Informasi", Andi, Yogyakarta.

Fathansyah. (2012). Basis Data.Informatika. Bandung.

Indrajani. (2011). Database Systems Case Study All In One. CV. Andi Offset. Yogyakarta.

Nugroho, Adi.(2011). "Perancangan Dan Implementasi Sistem Basis Data". CV. Andi Offset, Yogyakarta.

Nugroho Bunafit. (2016). MembuatAplikasi web Sistem Informasi Perpustakaan dengan PHP-MySQL dan Dreamweaver.Gava Media. Lampung Timur.

Priyadi, Yudi, (2014). Kolaborasi SQL \& ERD Dalam Implementasi Database. CV.Andi Offset. Yogyakarta.

Prasetio Adi.(2015). Buku Pintar Web Master. Mediakita.Jakarta Selatan.

Sidik Betha.(2012). Pemograman Wb dengan PHP.Informatika. Bandung.

Sutabri, Tata, (2012). Konsep Sistem Informasi. CV.Andi Offset. Yogyakarta. 